\title{
MULTI-CRITERIA OPTIMAL STRUCTURAL DESIGN UNDER UNCERTAINTY
}

\author{
JAMES L. BECK*, EDUARDO CHAN, AYHAN IRFANOGLU AND COSTAS PAPADIMITRIOU \\ Division of Engineering and Applied Science, California Institute of Technology, Pasadena, California 91125, U.S.A.
}

\begin{abstract}
SUMMARY
A general framework for multi-criteria optimal design is presented which is well suited for performancebased design of structural systems operating in an uncertain dynamic environment. A decision theoretic approach is used which is based on aggregation of preference functions for the multiple, possibly conflicting, design criteria. This allows the designer to trade off these criteria in a controlled manner during the optimization. Reliability-based design criteria are used to maintain user-specified levels of structural safety by properly taking into account the uncertainties in the modelling and seismic loads that a structure may experience during its lifetime. Code-based requirements are also easily incorporated into this optimal design process. The methodology is demonstrated with a simple example involving the design of a three-storey steel-frame building for which the ground motion uncertainty is characterized by a probabilistic response spectrum which is developed from available attenuation formulas and seismic hazard models. Copyright (C) 1999 John Wiley \& Sons, Ltd.
\end{abstract}

KEY WORDS: structural reliability; performance-based multi-criteria optimal design

\section{INTRODUCTION}

The decision-making process in the design of civil engineering systems requires the selection of the most promising choice for the design from a large set of possible alternatives, based on an evaluation using specified criteria reflecting the acceptability of a design. Such criteria usually include costs, structural engineering criteria, client preferences, social, political, legal and economic considerations, and liabilities from uncertain risks arising, for example, from construction practice and environmental loads such as earthquakes and strong winds. In particular, in order to be able to trade off reliability of performance and structural costs in the design process, the uncertainties in the structural response due to the uncertainties in the loads exciting the structure must be considered. ${ }^{1-5}$ These uncertainties, particularly for seismic loads, can be very influential factors in the design decisions.

\footnotetext{
* Correspondence to: James L. Beck, Division of Engineering and Applied Science, California Institute of Technology, Mail Code 104-44, Pasadena, CA 91125, U.S.A. E-mail: jlbeck@cco.caltech.edu

Contract/grant sponsor: CUREe-Kajima Research Program

Contract/grant sponsor: National Science Foundation; Contract/grant number: CMS-9796135
}

CCC 0098-8847/99/070741-21\$17.50

Copyright (C) 1999 John Wiley \& Sons, Ltd.
Received 21 October 1997 Revised 10 November 1998 
Numerous studies on single- and multi-objective reliability-based optimization with applications in the design of structural systems have been published, including References 6-11 and the contributions in the book edited by Adeli. ${ }^{12}$ The purpose of such studies is to find the optimal values of a set of design parameters that minimize one or more objective functions, such as total weight, total cost, or element or system failure probabilities, subject to constraints involving design conditions such as geometric constraints and strength criteria.

In the present work, a new framework for multi-criteria optimal design is presented which allows all the different design criteria to be traded off while accounting for modelling and loading uncertainties. It is demonstrated that existing reliability-based optimal design formulations can be viewed as special cases of the present approach. Moreover, the optimal solutions provided by the proposed framework belong to the multi-objective Pareto optimal set. ${ }^{13}$ A software package called CODA has been developed to implement the new multi-criteria optimal design framework using relatively new methodologies such as object-oriented programming, multi-criteria decision theory, stochastic optimization (including genetic algorithms) and reliability integral approximations. ${ }^{1}$ The development of this computer-aided multi-criteria optimal design tool allows the designer to rapidly evaluate and improve a proposed design by taking into account the major factors of interest related to design, construction and operation of a structure in the presence of risk.

In the following sections, the multi-criteria optimal design framework is presented in detail and then demonstrated with an example involving the design of a three-storey steel-frame building in the presence of seismic risk. The ground motion is characterized by a probabilistic response spectrum which is developed from available attenuation formulas and seismic hazard models. Optimal design results are presented for three different seismicity levels which involve trading off reliability of performance and structural cost while meeting code-based design criteria. A comparison is made between the optimal design for a continuous range of possible member sections and for a discrete set of AISC W-shape sections. ${ }^{14}$

\section{OPTIMAL DESIGN METHODOLOGY}

The design decision-making process is an iterative procedure where a preliminary design is cycled through stages of analysis, evaluation and revision to achieve a design which is optimum in some chosen sense. In the proposed optimal design methodology, a formal treatment of these three design stages is made so that the decision-making process can be implemented in software to aid the designer in selecting an optimal design. The methodology handles the key aspects of decision making in a design process in a consistent and rational way. Also, uncertainties related with the structural design are incorporated into the design process in a quantitative and explicit way so as to allow a formal treatment of their effects on the resulting design.

Structural design starts with an as comprehensive as possible description of the design problem. The designer must specify all design requirements, or design criteria, on which each design is to be judged, including the performance parameters involved in each design criteria. The designer then chooses a physical configuration as well as individual structural member geometrical and connection information to give a preliminary design. At this stage, the designer needs to specify all possible loading cases that the structure might experience during its lifetime. Clearly, the choice of these cases is of utmost importance since the structural design is greatly affected by the loadings considered. 
In the next stage of the design process, all structural performance parameters of the structure under the chosen loading cases are computed through some chosen analysis methods. It is important to realize that whichever response analysis method is used, for example, static, quasi-dynamic (e.g. response spectrum based) or dynamic analysis methods, there will be an uncertainty in the results computed due to the uncertainties in the loads applied to the structure and due to the uncertainties related with the modelling of the structure. A rational treatment of these uncertainties and their effects on the design can be made by using probabilistic analysis tools to incorporate them into the analysis of the structural performance.

The designer must then use the calculated performance parameter values to judge how well each design criterion is satisfied. In general, each such criterion will not be optimally satisfied by the preliminary design. The designer must then revise the initial design in order to obtain a better one by trying to better satisfy all the design criteria. In general, however, it will not be possible to optimally satisfy each criterion because some of them will be conflicting. Therefore, some compromise, or trade-off, must be performed when seeking a better design.

This process of analysis, evaluation and revision is repeated iteratively, and as long as it is necessary, to find a design which is considered to give the best compromise solution to all the design criteria. Descriptions of the methodologies involved in each design stage are given next.

\section{The analysis stage}

For the analysis stage of the optimal design methodology, the designer must specify what the design and performance parameters of interest are. These design and performance parameters are used to express the level of satisfaction of the design criteria in a quantitative manner so that an overall design performance measure can be computed for each design.

The design parameters, designated by a vector $\theta$, are those parameters of the design which are selected to be varied during the search for an optimal design. For example, design parameters may take the form of geometric information for the structural members, such as member cross-sectional dimensions. On the other hand, performance parameters, designated by a vector $\mathbf{q}$, represent quantities related to the 'performance' of the design, and can take the form of conventional structural parameters (e.g. stress, deflection, interstorey-drift) or other parameters (e.g. structural reliability, material cost of the structural system). Obviously, the performance parameters, $\mathbf{q}(\boldsymbol{\theta})$, are functions of the current design parameters, $\boldsymbol{\theta}$.

Structural performance parameters under 'deterministic' (code-based) loads can be computed using a finite-element model of the structure which is specified by the design parameters. The construction cost can be computed using a costing algorithm. On the other hand, reliabilitybased performance parameters, such as the uncertain peak lifetime interstorey-drift, must be analysed using probabilistic analysis tools and a probabilistic seismic hazard model, as described later.

\section{The evaluation stage}

The objective of the evaluation stage of the optimal design methodology is to obtain an overall design evaluation measure $\mu(\boldsymbol{\theta})$ for the design specified by the current value of the design parameter vector $\boldsymbol{\theta}$. This measure $\mu(\boldsymbol{\theta})$ serves as an objective function which, at the revision stage, is used to determine improved, or optimal, designs. 
In general, for evaluation of the design, the designer may wish to impose many different design criteria. Therefore, a multi-criteria decision methodology is required in which a design is quantitatively evaluated on the basis of each design criterion. ${ }^{13,15}$ Furthermore, since not every design criterion can be satisfied to its maximum extent simultaneously with the other design criteria, the methodology must allow a trade-off to occur between conflicting criteria in the optimization process. To be able to do the trading-off in a controlled manner, the designer should be given the freedom to set the relative importance of each design criterion explicitly.

In order to perform a quantitative evaluation of the current design, a preference function $\mu_{i}$, $i=1, \ldots, N_{\mathrm{c}}$, for each of the $N_{\mathrm{c}}$ design criteria is specified. The preference function $\mu_{i}\left(q_{i}\right)$ implements the corresponding design criterion in a 'soft' form. For the ith design criterion, the preference of a particular design $\boldsymbol{\theta}$ is evaluated through a measure $\mu_{i}\left(q_{i}(\boldsymbol{\theta})\right)$ of the performance parameter $q_{i}(\theta)$, where values of $\mu_{i}$ range from 0 to 1 . A larger value of $\mu_{i}$ implies that the designer prefers the corresponding design more than another which gives a smaller value of $\mu_{i}$, as judged by the $i$ th design criterion. A preference function can also be viewed as either giving a measure of the degree of satisfaction of a design criterion based on the calculated performance parameter values for a given design, or giving a measure of the degree of acceptability of a given design as judged by a design criterion. The extreme values $\mu_{i}\left(q_{i}(\theta)\right)=0$ and $\mu_{i}\left(q_{i}(\theta)\right)=1$ imply that, based on the $i$ th design criterion, the current design given by $\boldsymbol{\theta}$ is totally unsatisfactory or unacceptable and perfectly satisfactory or acceptable, respectively. As an illustration, a possible preference function for the interstorey drift under design code forces is given in Figure 2(e) where it is implied that interstorey-drift ratios lower than 2.7 per cent are perfectly acceptable while interstorey-drift ratios higher than 3 per cent are completely unacceptable.

In the evaluation process, the overall evaluation measure $\mu(\theta)$ of the design specified by $\theta$ is built up from the individual measures $\mu_{i}\left(q_{i}(\theta)\right)$ for each criterion through a preference aggregation rule. A preference aggregation rule is simply a functional relationship between the overall design evaluation measure and the individual preference values for all of the design criteria: $\mu=f\left(\mu_{1}, \mu_{2}, \ldots, \mu_{N_{\mathrm{c}}}\right)$, where $N_{\mathrm{c}}$ is the number of design criteria. ${ }^{15}$ An optimal design is therefore given by a design parameter vector $\theta$ which maximizes

$$
\mu(\boldsymbol{\theta})=f\left(\mu_{1}(\mathbf{q}(\boldsymbol{\theta})), \mu_{2}(\mathbf{q}(\boldsymbol{\theta})), \ldots, \mu_{N_{\mathrm{c}}}(\mathbf{q}(\boldsymbol{\theta}))\right)
$$

where it is to be understood that some of the preference functions $\mu_{i}$ may correspond to design parameter constraints in a 'soft' form and, therefore, these $\mu_{i}$ will depend directly on the design parameter values. Note that soft forms of the design criteria using preference functions are necessary if the design criteria are to be traded off against each other when determining the optimal design.

A preference aggregation rule should satisfy: ${ }^{16}$

1. The overall design evaluation measure $\mu$ lies in the unit interval $[0,1]$, with $\mu=1$ for a perfectly acceptable design and $\mu=0$ for a completely unacceptable design.

2. $\mu$ is a monotonically increasing continuous function of each $\mu_{i}$.

3. $\mu_{0}=f\left(\mu_{0}, \mu_{0}, \ldots, \mu_{0}\right)$ for $\mu_{0} \in[0,1]$.

4. $\mu=0$ if and only if $\mu_{i}=0$ for some $i$.

Axiom 1 gives the overall design evaluation measure $\mu$ the same range as the individual preference values $\mu_{i}, i=1, \ldots, N_{\mathrm{c}}$, corresponding to each of the design criteria. The continuity requirement in Axiom 2 ensures that a small change in preference for a design based on any of the design 
criteria results in only a small change in the overall design evaluation measure. In addition, the monotonicity in Axiom 2 guarantees that any improvement in a design based on any of the design criteria leads to an improvement in the overall design. Also, Axiom 3 is introduced because if all the preference functions for the design criteria have the same value $\mu_{0}$, then it would not be rational to give $\mu$ a higher or lower preference than the value $\mu_{0}$. Finally, Axiom 4 ensures that if a design is completely unacceptable on the basis of at least one design criterion, it is a completely unacceptable design in the overall sense. Conversely, a design is completely unacceptable only if it is so on the basis of at least one design criterion.

Although a preference aggregation rule should satisfy these four axioms, this does not give a unique solution for the function $f$. One solution is for $f$ to represent the minimum of the $\mu_{i}$ values, but this always focusses on improving the worst aspect of the design and does not allow trade-off of conflicting criteria. The preference aggregation rule selected here which satisfies the four axioms is the multiplicative trade-off strategy given by

$$
\mu(\boldsymbol{\theta})=\left[\mu_{1}(\boldsymbol{\theta})\right]^{m_{1}}\left[\mu_{2}(\boldsymbol{\theta})\right]^{m_{2}} \cdots\left[\mu_{N_{\mathrm{c}}}(\boldsymbol{\theta})\right]^{m_{N_{\mathrm{c}}}}
$$

where $m_{i}=w_{i} / \sum_{j=1}^{N_{\mathrm{c}}} w_{j}, i=1, \ldots, N_{\mathrm{c}}$, and $w_{i}$ is a positive importance weight assigned to the $i$ th design criterion which can be used to control its trade-off relative to the other criteria, that is, selected design criteria can be given more influence than others during optimization by assigning larger values to their importance weights. The choice of the values for these weights is up to the designer; however, software implementing the present methodology allows the designer to efficiently investigate the influence that different values for the weights have on the final optimal design and on the corresponding preference values for each design criterion. For example, if the designer wishes to perform an 'aggressive' code-based design which approaches close to the code drift limit of 3 per cent (Figure 2(e)), the importance weight for the building cost criterion should be made much larger than the importance weights for the other design criteria. This will give greater emphasis to reducing costs during the trade-off in the optimization.

The importance weights $w_{i}$ can be viewed from another perspective. Since there is no natural scale for preferences over all the diverse criteria, there is a need to be able to independently control their influence during the trade-off which occurs in the optimization process. In the case that the $w_{i}$ are all equal, the trade-off is governed by the inherent sensitivity of each $\mu_{i}$ with respect to $\boldsymbol{\theta}$. This 'natural' trade-off may not satisfy the designer, who may want to give greater influence to selected criteria. In this case, an importance weight, say $w_{j}$, can be increased, then the sensitivity of $\mu_{j}$ with respect to $\theta$ will be increased, which will give the $j$ th criterion more influence during the optimization.

A preference value less than unity for any design criterion indicates that in the corresponding optimal design, a trade-off or compromise had to be made because of conflicting design criteria which prevented the criterion from being simultaneously satisfied to its highest degree. The degree of compromise in any design criterion is reflected in the amount that its preference is reduced below unity.

\section{The revision stage}

In this step the design is revised until the optimal values of the design parameters $\boldsymbol{\theta}$, which maximize the overall preference function $\mu(\theta)$ in equation (2), are obtained.

In structural design problems, function (2) is usually defined over a discrete space for the variables $\boldsymbol{\theta}$. For example, steel I-beam sections are available commercially in only a discrete set of sizes such as the W-shapes in the AISC list. ${ }^{14}$ Thus, in this case, the optimization involving 
member sizes as design parameters must be done over this discrete set. A genetic algorithm called vGA is well suited to perform the discrete optimization. ${ }^{17}$

On the other hand, some design parameters may be defined in a continuous space so that computationally efficient techniques for optimizing continuous functions can be used. Deterministic and stochastic optimization methods are available for continuous function optimization. The well-known quasi-Newton method, ${ }^{19}$ which is often used for deterministic optimization of a continuous function, is not very suitable to handle the optimal design problem under consideration. The main reasons are that (1) the function $\mu(\theta)$ may be not sharply peaked along a curve or manifold in the parameter space, in which case the quasi-Newton converges slowly, or (2) it may not even be smooth because of numerical errors in computing the derivatives of $\mu(\theta)$, for example, in which case the quasi-Newton is not applicable, or (3) multiple local or global maxima of $\mu(\boldsymbol{\theta})$ may exist in which case the quasi-Newton method may only yield a local optimum which does not correspond to the globally optimal design.

Stochastic optimization methods are effective in handling complicated functions $\mu(\theta)$ and multiple maxima that may arise in the optimization process. Two stochastic optimization methods which are well suited for finding the global maximum of $\mu(\theta)$ are the adaptive random search method ${ }^{18}$ and the hybrid genetic algorithm. ${ }^{17}$ Although stochastic methods may have slower convergence and be computationally more expensive than the deterministic methods, they have the desirable feature of exploring a larger region in the space of parameters and, consequently, increasing the likelihood of finding a global maximum. This makes additional computational effort worthwhile when the optimum design is to be obtained. In particular, the hybrid genetic algorithm has been designed to decrease the computational effort by taking advantage of the accelerated convergence shown in the quasi-Newton method as it approaches a local optimum. Specifically, the hybrid genetic algorithm is based on using a genetic algorithm to explore the whole space of parameters and identify possible regions of multiple maxima. Once a region containing a local or global maximum of the function has been identified, it switches to the quasi-Newton method which greatly accelerates the convergence to the maximum as compa red to the convergence that can be achieved by a genetic algorithm alone. Of course, the optimal design may not always be unique but, in practice, it is sufficient if the optimization algorithm finds at least one global maximum.

Special cases of the methodology can be related to existing optimal design concepts. For example, it is easily shown that the optimal solution obtained by maximizing equation (2) belongs to the Pareto optimal set corresponding to the multiple 'objectives' $\mu_{1}, \ldots, \mu_{N_{\mathrm{c}}}{ }^{17}$ Also, consider the special case of the proposed methodology for which the preference function $\mu_{i}$ of the performance parameter $q_{i}$ decreases monotonically with $q_{i}$ so that $\mathrm{d} \mu_{i} / \mathrm{d} q_{i}<0$. If a 'hard' form of the preference functions is implemented in the design for all other design criteria, that is, for all $j \neq i, \mu_{j}=1$ for $q_{j, l} \leqslant q_{j} \leqslant q_{j, u}$ and $\mu_{j}=0$ otherwise, the unconstrained optimization problem in equation (2) is then equivalent to the constrained optimization problem in which $q_{i}(\boldsymbol{\theta})$ is minimized with respect to $\boldsymbol{\theta}$ while subject to the constraints $q_{j, l} \leqslant q_{j}(\theta) \leqslant q_{j, u},(j \neq i)$. This constrained optimization problem arises in existing optimal design methodologies involving the minimization of a cost or system failure probability subject to constraints on the reliability or cost, respectively, together with other design constraints. For example, $q_{i}$ could be the building cost and to reflect the fact that lower cost is preferred, the corresponding preference function $\mu_{i}$ of $q_{i}$ would be chosen to decrease monotonically with $q_{i}$. Thus, the condition $\mathrm{d} \mu_{i} / \mathrm{d} q_{i}<0$ would be satisfied. For reliability-based optimal design, a performance parameter $q_{j}$ could then represent the structural failure probability which should be below a specified threshold $q_{j, u}$. 


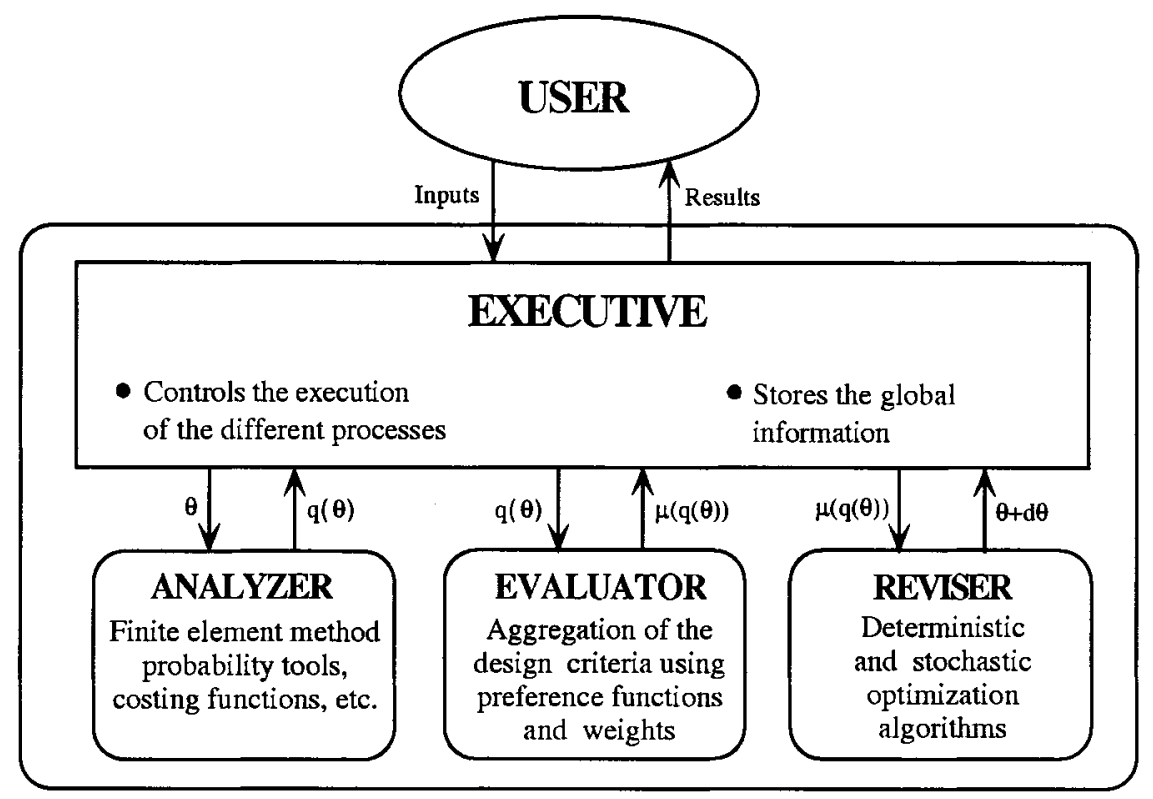

Figure 1. The principal modules and their interconnections in the software implementation, CODA, of the multi-criteria optimal design methodology

\section{Implementation of methodology in software}

The three design stages described above have been implemented in software called CODA. There is a separate module in the CODA software for each of the three stages involved, which are called the ANALYZER, EVALUATOR, and REVISER. ${ }^{1}$ There is also an EXECUTIVE module in CODA which acts as an interface between the original three modules and the user, controls the initialization and execution of the different processes, performs error-checking and errorrecovery, and stores the information associated with the analysis and design. The connection between the four modules are illustrated in Figure 1.

CODA was developed using object-oriented programming, a style of programming that establishes objects to represent and organize the information utilized by the program. CODA was implemented in this style to ensure that the code is modular and extensible to enhance the initial, and further, software development. For example, it is planned to extend the response and reliability analysis for linear models which is available in the current version of the ANALYZER to also treat the response and reliability analysis of non-linear hysteretic models.

\section{TREATMENT OF UNCERTAINTIES}

There are uncertainties in predicting structural response quantities of interest because of modelling errors and the uncertain loads that the completed structure will experience during its lifetime. 
The performance of the structure is usually judged in this case by safety considerations and a measure of safety is provided by component and system reliability. For example, one uncertain quantity is the peak interstorey-drift over the lifetime of the structure due to earthquakes. Therefore, in this case, a performance parameter can be chosen to be directly related to the interstorey-drift reliability. Available probabilistic analysis tools are then used in the analysis stage to calculate the structural reliability or, equivalently, the failure probability, corresponding to a specified interstorey-drift limit.

The first step in developing an expression for the probability of structural failure, designated by $F(\boldsymbol{\theta})$ for a design corresponding to $\boldsymbol{\theta}$, is to characterize the seismic hazard at the construction site by a set of ground motion parameters $\alpha$ (for example, peak ground acceleration, response spectrum ordinates, duration of motion, frequency content, etc.). For most probabilistic hazard models in use, these parameters depend, through appropriate 'attenuation' relationships, on a set of uncertain 'seismicity' variables, designated by a vector $\phi$, accounting for the uncertain regional seismic environment. For example, $\phi$ may include variables such as earthquake magnitude, fault dimensions, source parameters, epicentral distance, propagation path properties and local site conditions. The uncertain values of $\phi$ are described by a probability density function $p(\phi)$. For example, $p(\phi)$ might be chosen to model the probability of occurrence of an earthquake of a given magnitude and the probability of fault rupture at specific locations along a fault.

The required attenuation relationships are often derived by an empirical fit to the observed data. There is uncertainty associated with these attenuation models, even when $\phi$ is known, which is reflected by the scatter of the analysed data about the mean or median model predictions. Therefore, the attenuation relationship should actually give a probabilistic description $p(\alpha \mid \phi)$ of the relation between the ground motion parameters $\alpha$ and the seismicity parameters $\phi$.

Knowing the ground motion parameters $\alpha$ for a site does not completely specify the structural excitation. Furthermore, because of the presence of modelling errors, the structural model corresponding to a particular design $\boldsymbol{\theta}$ will not accurately predict the response of the structure should it be built. These uncertainties mean that a failure probability corresponding to a design $\boldsymbol{\theta}$ which is conditional on the ground motion parameters, designated by $F(\boldsymbol{\theta} \mid \boldsymbol{\alpha})$, must be set up. This can be done using probabilistic analysis tools. For example, the effect of the uncertainty in the seismic excitation at the site can be treated using random vibration analysis if the ground motion is modelled as a stochastic process depending on the parameters $\alpha$. On the other hand, stochastic finite-elements or methods for uncertain dynamical systems could be used to treat the modelling uncertainties. ${ }^{20,21}$

Finally, the uncertainties in the seismic environment, ground motion modelling and structural modelling can be combined using the total probability theorem to determine the total failure probability given an occurrence of an earthquake

$$
F(\boldsymbol{\theta})=\iint F(\boldsymbol{\theta} \mid \boldsymbol{\alpha}) p(\boldsymbol{\alpha} \mid \boldsymbol{\phi}) p(\boldsymbol{\phi}) \mathrm{d} \boldsymbol{\alpha} \mathrm{d} \boldsymbol{\phi}
$$

The failure probability over the lifetime of the structure can then be computed using a temporal occurrence model for the earthquake events, as illustrated later.

It is reasonable to numerically evaluate the multi-dimensional integral in equation (3) only if the dimension of the space of parameters is low. Otherwise, efficient importance sampling simulation methods ${ }^{22,23}$ or asymptotic methods ${ }^{24,25}$ can be used. In the case where only $\alpha$ and $\boldsymbol{\phi}$ are uncertain, $F(\boldsymbol{\theta} \mid \boldsymbol{\alpha})$ takes the value of either 0 or 1 and the failure probability integral (3) is 
transformed to the standard reliability integral which can be evaluated approximately using available FORM/SORM methods (e.g. References 26-28) or response surface methods. ${ }^{29}$

\section{EXAMPLE}

\section{Structural model and design criteria}

The optimal design methodology is demonstrated by applying it to the design of a three-storey, single-bay moment-resisting frame. The frame members are taken as steel I-beams with the length of the floor beams fixed at $6.1 \mathrm{~m}$ (240 in) and the height of the storey columns fixed at $3.05 \mathrm{~m}$ (120 in). The connections are modelled as rigid. Gravity loads are taken as $2 \cdot 873 \mathrm{e}-3 \mathrm{MPa}$ $\left(60 \mathrm{lb} / \mathrm{ft}^{2}\right)$ and $2 \cdot 394 \mathrm{e}-3 \mathrm{MPa}\left(50 \mathrm{lb} / \mathrm{ft}^{2}\right)$ for the dead and live loads, respectively, for each floor and the roof. An out-of-plane tributary width of $2.54 \mathrm{~m}$ (100 in) is used for the gravity load calculations.

The design parameters $\theta$ in the continuous case are the normalized member flange width $B / B_{\text {min }}$ and web depth $D / D_{\text {min }}$ for the beams and columns, i.e. $\boldsymbol{\theta}=\left(B_{\text {beam }} / B_{\text {min }}, D_{\text {beam }} / D_{\text {min }}\right.$, $\left.B_{\text {col }} / B_{\min }, D_{\text {col }} / D_{\text {min }}\right)$ where $B_{\min }=10.16 \mathrm{~cm}(4.0 \mathrm{in})$ and $D_{\min }=12.7 \mathrm{~cm}(5.0 \mathrm{in})$. The flange and web plate thicknesses are held fixed at $0.635 \mathrm{~cm}(0.25 \mathrm{in})$. In the discrete case, a subset of 128 of the AISC W-shapes is used. ${ }^{14}$ The objective is to determine $\theta$ so that the frame design is optimized according to design criteria involving the following performance parameters: flange width, web depth, building cost, probability of unacceptable peak lifetime interstorey-drift (drift risk) and code-based interstorey-drift and allowable stresses. The corresponding preference functions are shown in Figure 2. The importance weight for each design criterion is set to 1.0 for the aggregation of preference values in equation (2), unless otherwise stated. Notice that the first two design criteria shown in Figures 2(a) and 2(b) involve 'soft' constraints on the design parameters. Here, $B_{\max }=40.64 \mathrm{~cm}(16.0 \mathrm{in})$ and $D_{\max }=76.2 \mathrm{~cm}(30.0 \mathrm{in})$. The preference values in this case can be directly computed and incorporated in the preference aggregation rule (2).

For this example, the building cost $C$ is expressed simply as the sum of a construction (or fabrication) $\operatorname{cost} C_{\text {con }}$ and a material cost

$$
C=C_{\text {con }}+c_{\mathrm{s}} V
$$

where $c_{\mathrm{s}}$ is the material cost per unit steel volume and $V$ is the volume of steel used in the design. The variation in the construction costs for structural members of different sizes is assumed negligibly small, so that $C_{\text {con }}$ is essentially independent of $\boldsymbol{\theta}$. The preference function can then be expressed in terms of a normalized performance parameter

$$
q_{\mathrm{cost}}=\left(C-C_{\min }\right) /\left(C_{\max }-C_{\min }\right)=\left(V-V_{\min }\right) /\left(V_{\max }-V_{\min }\right)
$$

where $V_{\max }=0.3628 \mathrm{~m}^{3}\left(22140 \mathrm{in}^{3}\right)$ and $V_{\min }=0.0737 \mathrm{~m}^{3}\left(4500 \mathrm{in}^{3}\right)$ are the steel volumes corresponding to the maximum and minimum allowable member section sizes prescribed by the geometric constraints. The preference function for the building cost can therefore be expressed in terms of the steel volume $V(\boldsymbol{\theta})$ for a design given by $\boldsymbol{\theta}$. As shown in Figure 2(c), a linearly decreasing function is used to specify the preference values for the building cost in terms of the steel volume, with $\mu=1$ at the minimum allowable volume and $\mu=0$ at the maximum allowable volume. In the tables of results presented later, the building cost is reported as the normalized volume of steel, $V / V_{\min }$. 

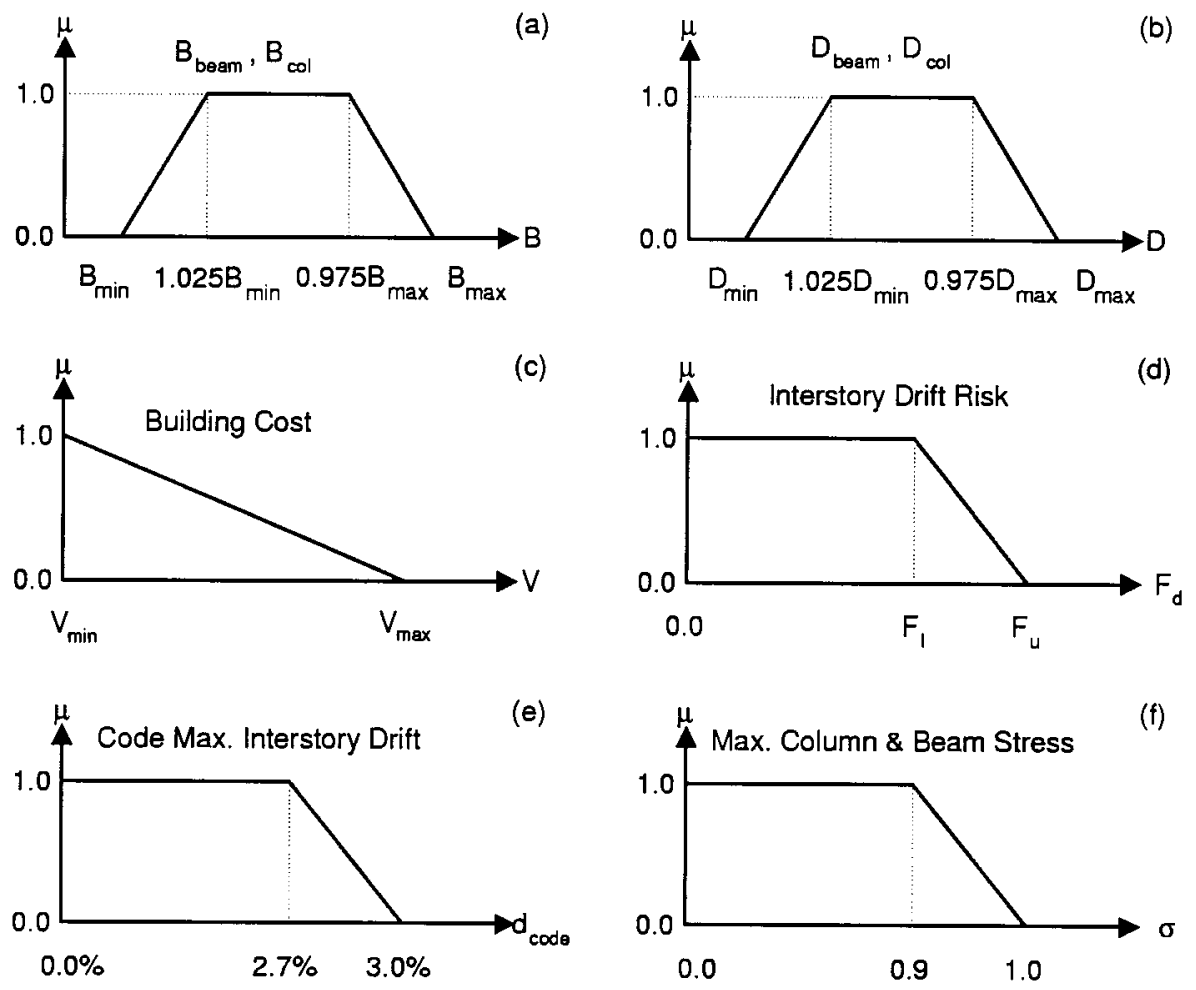

Figure 2. Preference functions for different design criteria

Design criteria corresponding to three modes of 'failure' are considered for the example building in this study. One is a reliability-based criterion involving the lifetime interstorey-drift risk, and the other two are code-based criteria involving interstorey-drift and column and beam stresses. The corresponding preference functions are shown in Figures 2(d), 2(e) and 2(f), respectively.

The code-based maximum allowable interstorey-drift is calculated using the $\mathrm{UBC}^{30}$ design response spectrum and employing standard modal analysis and combination methods. The parameters selected for the UBC requirements ${ }^{30}$ are seismic zone factor $Z=0 \cdot 4$, soil type $S=2$, importance factor $I=1.0$ and reduction factor $R_{w}=12$. The maximum interstorey-drift ratio $d_{\text {code }}$ must be less than 3 per cent under forces specified by the code response spectrum with no reduction by $R_{w}$. The requirements on the maximum column and beam stresses under the reduced (by $R_{w}$ ) code forces are given by $\sigma<1$, where $\sigma$ is the ratio of the induced stresses under the code forces to the AISC allowable stresses. ${ }^{14}$ These code design criteria are reflected in the choice of the corresponding preference functions in Figure 2. Figure 2(e) shows that a computed interstorey-drift ratio lower than 2.7 per cent is considered perfectly acceptable, while one higher than 3 per cent is considered completely unacceptable. Figure 2(f) shows that computed beam and column stresses less than 90 per cent of the code allowables are considered perfectly acceptable while those greater than the code allowables are considered completely unacceptable. 
For the reliability-based design criterion, unacceptable drift performance or 'failure' occurs if the maximum interstorey-drift ratio $d_{\max }$ exceeds a specified allowable drift ratio $d_{\text {allow }}=3$ per cent over the lifetime of the structure. The performance parameter is taken as the interstoreydrift risk, $F_{d}$, which is simply equal to the probability of exceeding $d_{\text {allow }}$ over the lifetime of the structure. As shown in Figure 2(d), the interstorey-drift risk $F_{d}$ is required to be less than a limit value $F_{u}$, with greatest preference $\mu=1$ given to risks (failure probabilities) which are less than a value $F_{l}$. In the numerical results, two cases are considered in order to examine their effects on the optimal design: $F_{l}=5$ per cent, $F_{u}=10$ per cent (the 5 per cent risk case) and $F_{l}=1$ per cent, $F_{u}=2$ per cent (the 1 per cent risk case). The risk $F_{d}$ is computed using a probabilistic seismic hazard model and probabilistic structural analysis tools. For simplicity, linear dynamics are used to approximately compute the deformations even though for large drifts the structural response would involve inelastic behaviour.

In the example, it is found that the optimal design is governed by a trade-off between the building cost and the lifetime interstorey-drift risk. Although the code-based requirements do not control the optimal design in this case, in general, it is important to include them to ensure that the legal requirements are satisfied by the optimal design. The difference between the lifetime interstorey-drift risk and code-based interstorey-drift is that the former one gives the failure probability of the structure by explicitly considering the uncertainties in future loadings using a site-specific seismic environment, while the code-based calculations consider the deterministic design response spectrum specified in the code. The explicit consideration of the failure probability is of great importance in the design process since it provides flexibility in specifying preferences on the reliability of the structure. Also, since interstorey-drift can be correlated with structural and non-structural damage, it can be viewed as a proxy for a design criterion in terms of uncertain lifetime earthquake losses. Of course, if desired, these lifetime losses can be included directly in a reliability-based design criterion.

As an alternative approach to optimal design under seismic risk, the objective function to be minimized can be set equal to the expected total cost over the lifetime of the building, which involves summing the construction cost and the expected lifetime earthquake losses. ${ }^{3}$ In the terminology of decision theory, this assumes a 'risk neutral' approach. ${ }^{15}$ In contrast, the multi-criteria methodology presented in this work allows the designer to give more weight to construction costs or to expected lifetime earthquake losses, depending on the building owner's attitude towards risk, which might not be a 'risk neutral' one.

\section{Probabilistic seismic hazard model}

In the probabilistic structural analysis considered here, a response spectrum approach is used to compute the response quantities of interest. The ground motion is characterized by the pseudo-velocity response spectrum $S_{\mathrm{V}}(T, \zeta)$ where $T$ is the period and $\zeta$ is the damping ratio of a single degree-of-freedom linear oscillator. The attenuation formula proposed by Boore et al. ${ }^{31,32}$ is used to model $S_{\mathrm{V}}(T, \zeta)$ in terms of earthquake magnitude and epicentral distance. The attenuation relationship is given as

$$
\log _{10}\left(S_{\mathrm{V}}(T, \zeta)\right)=\log _{10}\left(\hat{S}_{\mathrm{V}}(T, \zeta)\right)+\varepsilon(T, \zeta)
$$

where

$$
\log _{10}\left(\hat{S}_{\mathrm{V}}(T, \zeta)\right)=\hat{b}_{1}+\hat{b}_{2}(M-6)+\hat{b}_{3}(M-6)^{2}+\hat{b}_{4} r+\hat{b}_{5} \log (r)+\hat{b}_{6} G_{b}+\hat{b}_{7} G_{c}
$$


Here $r=\sqrt{R^{2}+h^{2}}$, where $R$ is the epicentral distance and $h$ is a fictitious event depth determined by the regression analysis; $G_{b}$ and $G_{c}$ are soil-type parameters which take a value 0 or 1 depending on the soil classification at the site. The best estimates of the parameters $\hat{b}_{i} \equiv \hat{b}_{i}(T, \zeta)$ appearing in the model for $\hat{S}_{\mathrm{V}}(T, \zeta)$ have been determined by Boore et al. ${ }^{31,32}$ by regression analysis of a large database of accelerograms for four different damping values $(\zeta=2,5,10$ and 20 per cent) and 46 different period values ranging from $0 \cdot 1$ to $2 \cdot 0 \mathrm{~s}$. For a complete description of all variables appearing in the attenuation formula (7), the reader is referred to Boore et l. $^{32}$ The function $\varepsilon(T, \zeta)$ in equation (6) represents the uncertain model error in the actual spectral amplitudes $S_{\mathrm{V}}(T, \zeta)$ compared with the estimated amplitudes $\hat{S}_{\mathrm{V}}(T, \zeta)$ from the model. The probability density function for $\varepsilon(T, \zeta)$ is assumed to follow a Gaussian distribution over the range of periods analysed, with zero mean and variance given in Boore et al. ${ }^{32}$

In this study, only the epicentral distance $R$ and the earthquake magnitude $M$ are considered as uncertain 'seismicity' variables. The probability distribution for these parameters is derived by assuming a simple seismicity model as follows. The earthquake sources are point sources located in a circular area with a radius of $R_{\max }$ centred at the site where the building is located. It is assumed that an earthquake is equally likely to occur at any point inside this circular source region, so the probability $p(R) \mathrm{d} R$ is simply the ratio of the area of a strip of width $\mathrm{d} R$ located $R$ distance away from the centre to the area of the circle with radius $R_{\max }$, yielding the probability density function

$$
p(R)=2 R / R_{\max }^{2}
$$

The probability density function $p(M)$ for the earthquake magnitude is based on a truncated Gutenberg-Richter relationship ${ }^{33}$

$$
p(M)=b^{\prime} \mathrm{e}^{-b^{\prime} \boldsymbol{M}} /\left(\mathrm{e}^{-b^{\prime} M_{\min }}-\mathrm{e}^{-b^{\prime} M_{\max }}\right)
$$

where $M_{\min }$ and $M_{\max }$ are the regional lower and upper bounds for the earthquake magnitude, and $b^{\prime}=b \log _{e}(10)$. The expected number of events per annum falling into the magnitude range considered is $v=10^{a-b M_{\min }}-10^{a-b M_{\max }}$. The following data are used for the parameters of the seismicity model: $R_{\max }=50 \mathrm{~km}, M_{\min }=5.0, M_{\max }=7 \cdot 7, b=1.0$ and $a$ is chosen to give a desired value of $v$, the seismicity rate. The epicentral distance and the earthquake magnitude are assumed to be stochastically independent, although a more refined probability could be based on extended earthquake sources and allow correlation between $R$ and $M$ for larger values of $M$.

\section{Reliability computations}

The uncertain parameter set $\boldsymbol{\phi}$ for the ground motion model describing $S_{\mathrm{V}}(T, \zeta)$ consists of the magnitude $M$ and the epicentral distance $R$, so the probability density function corresponding to $p(\boldsymbol{\alpha} \mid \boldsymbol{\phi})$ in the general theory described earlier is $p\left(\mathbf{S}_{\mathrm{V}} \mid M, R\right)$ where $\mathbf{S}_{\mathrm{V}}=\left[S_{\mathrm{V}}\left(T_{1}, \zeta_{1}\right), \ldots\right.$, $\left.S_{\mathrm{V}}\left(T_{n}, \zeta_{n}\right)\right]^{\mathrm{T}}$ and $n$ is the number of modes contributing significantly to the displacement response. A probability model which assumes stochastic independence of the spectral ordinates is used, so

$$
p\left(\mathbf{S}_{\mathrm{V}} \mid M, R\right)=\prod_{j=1}^{n} p\left(S_{\mathrm{V}}\left(T_{j}, \zeta_{j}\right) \mid M, R\right)
$$


where each probability density function in the product is a log-normal distribution implied by equation (6).

Since the ground motion is characterized by the pseudo-velocity response spectrum $S_{\mathrm{V}}(T, \zeta)$, a response spectrum analysis is used to compute the peak interstorey-drift $d_{i}$ of the $i$ th storey. To this end, available modal combination rules may be used to estimate $d_{i}$ from the maximum effective modal drifts $\xi_{i j}$ for each mode $j .{ }^{34}$ Assuming well-separated structural modal frequencies, one obtains $d_{i}=\left(\xi_{i 1}^{2}+\cdots+\xi_{i n}^{2}\right)^{1 / 2}$, where $\xi_{i j}=\beta_{i j} S_{\mathrm{V}}\left(T_{j}, \zeta_{j}\right), T_{j}$ is the modal period, $\zeta_{j}$ is the modal damping ratio, and $\beta_{i j}$ is the corresponding effective modal participation factor for the $i$ th floor, which depends on the $j$ th modal properties. These properties are computed through an eigenvalue analysis of the structure corresponding to a particular $\boldsymbol{\theta}$. Structural modelling errors and the uncertainty in the estimate for $d_{i}$ given by the modal combination rule are ignored in this example, but these effects could be included.

The drift risk $F_{d}(\boldsymbol{\theta}, t)=P\left(d_{\max }>d_{\text {allow }} \mid \boldsymbol{\theta}, t\right)$ over the lifetime $t$ of the structure is computed using a probabilistic structural analysis as follows. Assuming that the occurences of earthquake events follow a Poisson arrival process, the probability that the structural safety requirements are not satisfied during the lifetime $t$ years of the structure, is given by

$$
F_{d}(\boldsymbol{\theta}, t)=1-\exp [-v F(\boldsymbol{\theta}) t]
$$

where

$$
F(\boldsymbol{\theta})=P\left(d_{\text {max }}>d_{\text {allow }} \mid \boldsymbol{\theta}\right)=P\left(\bigcup_{i=1}^{n}\left\{d_{i}>d_{\text {allow }}\right\} \mid \boldsymbol{\theta}\right)
$$

is the failure probability, given an occurrence of an event. Note that $F(\boldsymbol{\theta})$ can be simplified to the form (3), where $\boldsymbol{\alpha}=\mathbf{S}_{\mathrm{V}}, \boldsymbol{\phi}=(M, R)$ and $F(\boldsymbol{\theta} \mid \boldsymbol{\alpha})=P\left(d_{\max }>d_{\text {allow }} \mid \mathbf{S}_{\mathrm{V}}, \boldsymbol{\theta}\right)$. Under the previous assumption that the interstorey-drifts are known once $\mathbf{S}_{\mathrm{V}}$ and $\boldsymbol{\theta}$ are given, it is clear that the resulting conditional failure probability $P\left(d_{\max }>d_{\text {allow }} \mid \mathbf{S}_{\mathrm{V}}, \boldsymbol{\theta}\right)$ is either 1 or 0 , depending on whether the safety levels have been exceeded or not, so the failure probability is given as

$$
F(\boldsymbol{\theta})=\int_{\bigcup_{i=1}^{n} g_{i}<0} p\left(\mathbf{S}_{\mathrm{V}} \mid M, R\right) p(M) p(R) \mathrm{d} \mathbf{S}_{\mathrm{V}} \mathrm{d} M \mathrm{~d} R
$$

where $g_{i}=g_{i}\left(\mathbf{S}_{\mathbf{V}}, \boldsymbol{\theta}\right)=d_{\text {allow }}-d_{i}\left(\mathbf{S}_{\mathbf{V}}, \boldsymbol{\theta}\right)$. The numerical integration involved in computing $F(\boldsymbol{\theta})$ can be a time-consuming operation. Alternatively, integral (13) is in the form of the classical system reliability problem for a series of components in which if any of the components fails, that is, if any $d_{i}\left(\mathbf{S}_{\mathrm{V}}, \boldsymbol{\theta}\right)>d_{\text {allow }}$, the system is considered failed. The component failure probability, given an occurrence of an event, is given by

$$
F_{i}(\boldsymbol{\theta})=\int_{g_{i}<0} p\left(\mathbf{S}_{\mathrm{V}} \mid M, R\right) p(M) p(R) \mathrm{d} \mathbf{S}_{\mathrm{V}} \mathrm{d} M \mathrm{~d} R
$$

and this integration could be efficiently performed using first- and second-order reliability methods. ${ }^{26}$ In this study, however, the asymptotic second-order reliability approximation given by Papadimitriou et al. ${ }^{24,25}$ is used to calculate the resulting component failure probabilities. In the numerical results that follow, it will be demonstrated that considering only one failure surface corresponding to the highest component failure probability results in a good approximation of the system reliability for the type of design problem discussed herein. 
Numerical results

For the numerical study, the modal damping ratios are chosen to be $\zeta_{i}=0.05$ for all contributing modes. A lifetime of $t=50$ years is considered. The results in Table I correspond to a seismicity rate $v=1$ event per annum and the case where beams and columns have the same cross-sectional dimensions, i.e. $B_{\text {beam }}=B_{\text {col }}=B, D_{\text {beam }}=D_{\text {col }}=D$, and so $\theta=\left(B / B_{\text {min }}, D / D_{\text {min }}\right)$. Results are shown for both the 5 and 1 per cent risk cases described earlier. As expected, the optimal design for 1 per cent drift risk gives larger member sizes than the 5 per cent risk case does. The Uniform Building Code (UBC) drift and strength requirements ${ }^{30}$ are not included as design criteria for the results in Table I. The results for one, two and three contributing structural modes are obtained using the asymptotic approximation of the failure probability integral. ${ }^{25}$ In the case of one structural mode, a numerical integration scheme is also used to provide an accuracy check for the more efficiently calculated asymptotic results. It is observed from Table I that the asymptotic approximation gives results similar to those obtained from numerical integration, especially for higher reliability requirements. Also, it can be seen that the second and third translational modes do not have a significant effect on the optimal design of the three-storey structure considered in this study.

Note that in Table I, and in other cases shown below, the optimal flange width $B$ is always $1.025 B_{\min }$, which corresponds to the lower corner of the preference function for $B$ shown in Figure 2(a). This occurs because it is more cost-effective to provide the necessary bending stiffness by increasing the web depth $D$ rather than the flange width $B$. However, if $B$ is reduced below $1.025 B_{\min }$, the rate of reduction in the preference in Figure 2(a) outweighs the improvement in the cost preference in Figure 2(c).

In Table I, $F_{d, i}(i=1,2,3)$ denote the drift risk for the $i$ th storey over the lifetime $t$ of the structure. Note that the interstorey-drift risk $F_{d, 2}$ for the second storey governs the design for the example problem at hand. This is because of the rotational constraints at the base of the first storey columns. Specifically, it was found that the failure regions defined by the failure surfaces $g_{1}\left(\mathbf{S}_{\mathbf{V}}\right)=0$ and $g_{3}\left(\mathbf{S}_{\mathbf{V}}\right)=0$ for the first and third storeys, respectively, are subsets of the failure region defined by the dominant failure surface $g_{2}\left(\mathbf{S}_{\mathbf{V}}\right)=0$ in the region of high probability. ${ }^{35}$ This can be seen from Figure 3 which gives the composite plot of the failure surfaces $g_{1}\left(\mathbf{S}_{\mathrm{V}}\right)=0$, $g_{2}\left(\mathbf{S}_{\mathbf{V}}\right)=0, g_{3}\left(\mathbf{S}_{\mathbf{V}}\right)=0$ in the space of the pseudo-velocity responses of the first and second modes of the structure, and the contour plots of the respective probabilities $p\left(\mathbf{S}_{\mathrm{V}}\right)$ of observing those pseudo-velocities for the given seismic environment model. The probability density function for $\mathbf{S}_{\mathrm{V}}$ shown in Figure 3 is given by

$$
p\left(\mathbf{S}_{\mathrm{V}}\right)=\int_{M} \int_{R} p\left(\mathbf{S}_{\mathbf{V}} \mid M, R\right) p(M) p(R) \mathrm{d} R \mathrm{~d} M
$$

where the integration is carried out numerically. From the demonstration in Figure 3 it is clear that the contributions to the system failure probability $F_{d}$ from the failure regions defined by the surfaces $g_{1}\left(\mathbf{S}_{\mathrm{V}}\right)=0$ and $g_{3}\left(\mathbf{S}_{\mathrm{V}}\right)=0$ for the first and third storey drifts are negligible.

In Table II, the case of four design parameters, $\boldsymbol{\theta}=\left(B_{\text {beam }} / B_{\min }, D_{\text {beam }} / D_{\text {min }}, B_{\text {col }} / B_{\text {min }}\right.$, $D_{\text {col }} / D_{\text {min }}$ ), is presented which allows beam and column cross-sectional dimensions to be different but all beams must have the same cross-section and so do all columns. Comparing the building costs (steel volumes) in Tables I and II, it is observed that by treating the sizes of beams and columns independently, the optimal designs are slightly less costly, as expected. However, in both 
Table I. Optimal design for $v=1$; Beams and columns have same sections

\begin{tabular}{|c|c|c|c|c|c|c|c|c|c|c|}
\hline \multirow[b]{3}{*}{ Criteria } & \multicolumn{8}{|c|}{ Continuous optimization } & \multirow{2}{*}{\multicolumn{2}{|c|}{$\begin{array}{l}\text { Genetic algorithm } \\
\text { 1-mode (numer.) }\end{array}$}} \\
\hline & \multicolumn{2}{|c|}{ 1-mode (numer.) } & \multicolumn{2}{|c|}{ 1-mode (asymp.) } & \multicolumn{2}{|c|}{ 2-mode (asymp.) } & \multicolumn{2}{|c|}{ 3-mode (asymp.) } & & \\
\hline & Value & $\mu$ & Value & $\mu$ & Value & $\mu$ & Value & $\mu$ & Value & $\mu$ \\
\hline \multicolumn{11}{|c|}{$5 \%$ risk } \\
\hline$B / B_{\min }$ & $1 \cdot 025$ & $1 \cdot 0000$ & $1 \cdot 025$ & $1 \cdot 0000$ & $1 \cdot 025$ & $1 \cdot 0000$ & $1 \cdot 025$ & $1 \cdot 0000$ & $\mathrm{~W} 8 \times 18$ & $1 \cdot 0000$ \\
\hline$D / D_{\min }$ & $1 \cdot 947$ & $1 \cdot 0000$ & $1 \cdot 741$ & $1 \cdot 0000$ & $1 \cdot 742$ & $1 \cdot 0000$ & $1 \cdot 743$ & $1 \cdot 0000$ & & $1 \cdot 0000$ \\
\hline$V / V_{\min }$ & $1 \cdot 395$ & $0 \cdot 8992$ & $1 \cdot 312$ & 0.9203 & $1 \cdot 313$ & $0 \cdot 9202$ & $1 \cdot 313$ & $0 \cdot 9201$ & 1.659 & $0 \cdot 8318$ \\
\hline$F_{d, 1}$ & $0 \cdot 0163$ & - & $0 \cdot 0214$ & - & $0 \cdot 0220$ & - & $0 \cdot 0220$ & - & $0 \cdot 0171$ & - \\
\hline$F_{d, 2}$ & $0 \cdot 0500$ & - & $0 \cdot 0500$ & - & $0 \cdot 0500$ & - & $0 \cdot 0500$ & - & 0.0522 & - \\
\hline$F_{d, 3}$ & $0 \cdot 0179$ & - & 0.0228 & - & $0 \cdot 0247$ & - & $0 \cdot 0247$ & - & $0 \cdot 0187$ & - \\
\hline$F_{d}$ & $0 \cdot 0500$ & 1.0000 & $0 \cdot 0500$ & 1.0000 & $0 \cdot 0500$ & $1 \cdot 0000$ & 0.0500 & 1.0000 & $0 \cdot 0522$ & 0.9568 \\
\hline Overall & & 0.9738 & & 0.9794 & & 0.9794 & & 0.9794 & & 0.9445 \\
\hline Period & \multicolumn{2}{|c|}{$T_{1}=1 \cdot 106 \mathrm{~s}$} & \multicolumn{2}{|c|}{$T_{1}=1 \cdot 260 \mathrm{~s}$} & \multicolumn{2}{|c|}{$\begin{array}{l}T_{1}=1 \cdot 260 \mathrm{~s} \\
\text { risk }\end{array}$} & \multicolumn{2}{|c|}{$T_{1}=1 \cdot 258 \mathrm{~s}$} & \multicolumn{2}{|c|}{$T_{1}=1 \cdot 121 \mathrm{~s}$} \\
\hline$B / B_{\min }$ & $1 \cdot 025$ & $1 \cdot 0000$ & $1 \cdot 025$ & 1.0000 & 1.025 & $1 \cdot 0000$ & $1 \cdot 025$ & 1.0000 & $\mathrm{~W} 14 \times 22$ & 1.0000 \\
\hline$D / D_{\min }$ & $2 \cdot 797$ & 1.0000 & $2 \cdot 734$ & $1 \cdot 0000$ & $2 \cdot 734$ & $1 \cdot 0000$ & $2 \cdot 734$ & 1.0000 & & 1.0000 \\
\hline$V / V_{\min }$ & $1 \cdot 735$ & $0 \cdot 8125$ & $1 \cdot 709$ & $0 \cdot 8190$ & $1 \cdot 710$ & $0 \cdot 8190$ & $1 \cdot 710$ & $0 \cdot 8189$ & $2 \cdot 034$ & $0 \cdot 7362$ \\
\hline$F_{d, 1}$ & 0.0025 & - & 0.0034 & - & $0 \cdot 0035$ & - & 0.0035 & - & $0 \cdot 0011$ & - \\
\hline$F_{d, 2}$ & $0 \cdot 0100$ & - & $0 \cdot 0100$ & - & $0 \cdot 0100$ & - & $0 \cdot 0100$ & - & $0 \cdot 0052$ & - \\
\hline$F_{d, 3}$ & 0.0029 & - & 0.0038 & - & 0.0039 & - & 0.0039 & - & 0.0013 & - \\
\hline$F_{d}$ & $0 \cdot 0100$ & 1.0000 & $0 \cdot 0100$ & $1 \cdot 0000$ & $0 \cdot 0100$ & $1 \cdot 0000$ & $0 \cdot 0100$ & 1.0000 & 0.0052 & 1.0000 \\
\hline Overall & & 0.9494 & & 0.9513 & & 0.9513 & & 0.9513 & & 0.9263 \\
\hline Period & \multicolumn{2}{|c|}{$T_{1}=0.722 \mathrm{~s}$} & \multicolumn{2}{|c|}{$T_{1}=0.742 \mathrm{~s}$} & \multicolumn{2}{|c|}{$T_{1}=0.742 \mathrm{~s}$} & \multicolumn{2}{|c|}{$T_{1}=0.742 \mathrm{~s}$} & \multicolumn{2}{|c|}{$T_{1}=0.632 \mathrm{~s}$} \\
\hline
\end{tabular}




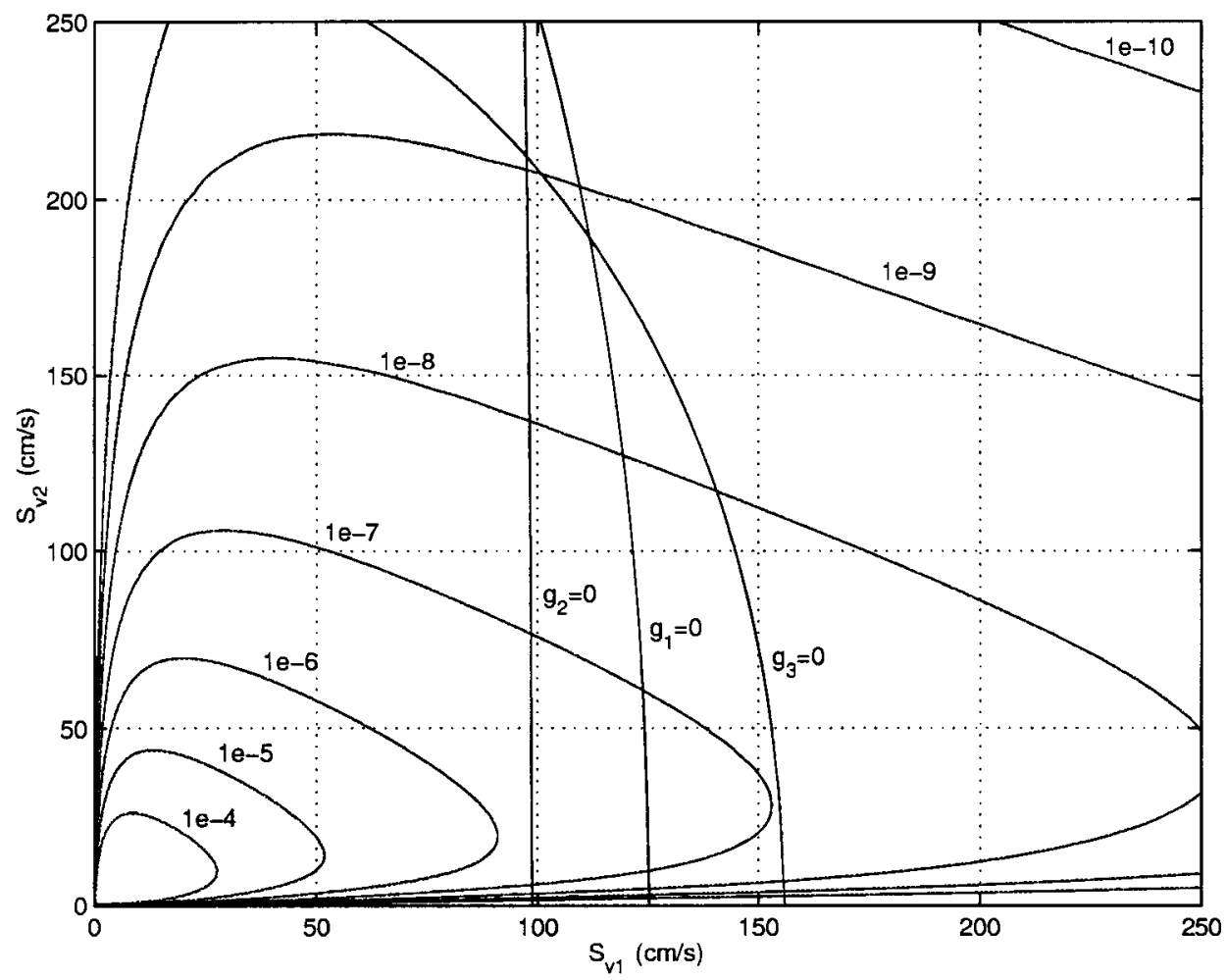

Figure 3. Interstorey-drift failure surfaces for 5 per cent risk, and $p\left(S_{\mathrm{V} 1}, S_{\mathrm{V} 2}\right)$ contours

cases, the dynamics of the resulting optimal structures are similar as illustrated by the similar fundamental periods in Tables I and II.

The optimal design applying the vGA genetic algorithm to a discrete optimization over a set of 128 of the more relevant AISC W-shape steel sections is also presented in the last column of Tables I and II. An increase in building cost (corresponding to 20 per cent or so increase in steel volume) occurs compared with the continuous optimization case. This is due to the limited variety of steel-section sizes in the discrete case.

In Table III, the effect of the regional seismicity rate on the optimal design is investigated. Results are presented for the three seismicity rates corresponding to $v=0 \cdot 5,1$ and 2 events per annum and for 5 and 1 per cent drift risk cases. As expected, higher seismicity or lower risk requirements lead to larger structural members. Note that the UBC requirements reflected in Figures 2(e) and 2(f) are also included as design criteria. The dynamic lateral-load calculation procedure for the code-based performance parameters, i.e. maximum column stress, maximum beam stress and maximum interstorey-drift, in Table III is based on the response spectra described in the 1994 UBC. ${ }^{30}$ For all six cases presented in Table III, the drift reliability requirement is found to be more stringent than what the UBC demands, so the UBC requirements have no influence on the final design. This can be seen from the fact that the code stress 
Table II. Optimal design for $v=1$; Beams and columns have different sections

\begin{tabular}{|c|c|c|c|c|c|c|c|c|c|c|}
\hline \multirow[b]{3}{*}{ Criteria } & \multicolumn{8}{|c|}{ Continuous optimization } & \multirow{2}{*}{\multicolumn{2}{|c|}{$\begin{array}{l}\text { Genetic algorithm } \\
\text { 1-mode (numer.) }\end{array}$}} \\
\hline & \multicolumn{2}{|c|}{ 1-mode (numer.) } & \multicolumn{2}{|c|}{ 1-mode (asymp.) } & \multicolumn{2}{|c|}{ 2-mode (asymp.) } & \multicolumn{2}{|c|}{ 3-mode (asymp.) } & & \\
\hline & Value & $\mu$ & Value & $\mu$ & Value & $\mu$ & Value & $\mu$ & Value & $\mu$ \\
\hline \multicolumn{11}{|c|}{$5 \%$ risk } \\
\hline$B_{\text {beam }} / B_{\text {min }}$ & $1 \cdot 025$ & $1 \cdot 0000$ & $1 \cdot 025$ & $1 \cdot 0000$ & $1 \cdot 025$ & $1 \cdot 0000$ & $1 \cdot 025$ & $1 \cdot 0000$ & $\mathrm{~W} 8 \times 18$ & $1 \cdot 0000$ \\
\hline$D_{\text {beam }} / D_{\text {min }}$ & $2 \cdot 200$ & $1 \cdot 0000$ & 1.959 & $1 \cdot 0000$ & 1.958 & $1 \cdot 0000$ & $1 \cdot 952$ & $1 \cdot 0000$ & & $1 \cdot 0000$ \\
\hline$B_{\mathrm{col}} / B_{\min }$ & $1 \cdot 025$ & $1 \cdot 0000$ & $1 \cdot 025$ & $1 \cdot 0000$ & $1 \cdot 025$ & $1 \cdot 0000$ & $1 \cdot 025$ & $1 \cdot 0000$ & $\mathrm{~W} 8 \times 18$ & $1 \cdot 0000$ \\
\hline$D_{\text {col }} / D_{\min }$ & $1 \cdot 622$ & $1 \cdot 0000$ & $1 \cdot 466$ & $1 \cdot 0000$ & $1 \cdot 469$ & $1 \cdot 0000$ & $1 \cdot 479$ & $1 \cdot 0000$ & & $1 \cdot 0000$ \\
\hline$V / V_{\min }$ & $1 \cdot 380$ & $0 \cdot 9030$ & $1 \cdot 301$ & $0 \cdot 9232$ & $1 \cdot 301$ & $0 \cdot 9231$ & $1 \cdot 302$ & $0 \cdot 9229$ & $1 \cdot 659$ & $0 \cdot 8318$ \\
\hline$F_{d, 1}$ & $0 \cdot 0252$ & - & $0 \cdot 0291$ & - & 0.0298 & - & $0 \cdot 0294$ & - & $0 \cdot 0171$ & - \\
\hline$F_{d, 2}$ & $0 \cdot 0500$ & - & $0 \cdot 0500$ & - & $0 \cdot 0500$ & - & $0 \cdot 0500$ & - & 0.0522 & - \\
\hline$F_{d, 3}$ & $0 \cdot 0129$ & - & $0 \cdot 0182$ & - & $0 \cdot 0200$ & - & $0 \cdot 0201$ & - & $0 \cdot 0187$ & - \\
\hline$F_{d}$ & $0 \cdot 0500$ & $1 \cdot 0000$ & $0 \cdot 0500$ & $1 \cdot 0000$ & $0 \cdot 0500$ & $1 \cdot 0000$ & $0 \cdot 0500$ & $1 \cdot 0000$ & $0 \cdot 0522$ & $0 \cdot 9568$ \\
\hline Overall & & 0.9831 & & $0 \cdot 9868$ & & 0.9868 & & 0.9867 & & 0.9627 \\
\hline Period & \multicolumn{2}{|c|}{$T_{1}=1 \cdot 128 \mathrm{~s}$} & \multicolumn{2}{|c|}{$T_{1}=1 \cdot 280 \mathrm{~s}$} & \multicolumn{2}{|c|}{$T_{1}=1 \cdot 278 \mathrm{~s}$} & \multicolumn{2}{|c|}{$T_{1}=1 \cdot 276 \mathrm{~s}$} & \multicolumn{2}{|c|}{$T_{1}=1 \cdot 121 \mathrm{~s}$} \\
\hline \multicolumn{11}{|c|}{$1 \%$ risk } \\
\hline$B_{\text {beam }} / B_{\text {min }}$ & $1 \cdot 025$ & $1 \cdot 0000$ & $1 \cdot 025$ & $1 \cdot 0000$ & $1 \cdot 025$ & $1 \cdot 0000$ & $1 \cdot 025$ & $1 \cdot 0000$ & $\mathrm{~W} 14 \times 22$ & $1 \cdot 0000$ \\
\hline$D_{\text {beam }} / D_{\text {min }}$ & $3 \cdot 151$ & $1 \cdot 0000$ & $3 \cdot 076$ & $1 \cdot 0000$ & $3 \cdot 074$ & $1 \cdot 0000$ & $3 \cdot 069$ & $1 \cdot 0000$ & & $1 \cdot 0000$ \\
\hline$B_{\mathrm{col}} / B_{\min }$ & $1 \cdot 025$ & $1 \cdot 0000$ & $1 \cdot 025$ & $1 \cdot 0000$ & $1 \cdot 025$ & $1 \cdot 0000$ & $1 \cdot 025$ & $1 \cdot 0000$ & $\mathrm{~W} 14 \times 22$ & $1 \cdot 0000$ \\
\hline$D_{\text {col }} / D_{\min }$ & $2 \cdot 353$ & $1 \cdot 0000$ & $2 \cdot 299$ & $1 \cdot 0000$ & $2 \cdot 303$ & $1 \cdot 0000$ & $2 \cdot 309$ & $1 \cdot 0000$ & & $1 \cdot 0000$ \\
\hline$V / V_{\min }$ & $1 \cdot 717$ & $0 \cdot 8172$ & 1.691 & $0 \cdot 8237$ & $1 \cdot 691$ & 0.8236 & 1.692 & $0 \cdot 8236$ & $2 \cdot 034$ & 0.7362 \\
\hline$F_{d, 1}$ & 0.0042 & - & 0.0051 & - & $0 \cdot 0051$ & - & 0.0051 & - & $0 \cdot 0011$ & - \\
\hline$F_{d, 2}$ & $0 \cdot 0100$ & - & $0 \cdot 0100$ & - & $0 \cdot 0100$ & - & $0 \cdot 0100$ & - & $0 \cdot 0052$ & - \\
\hline$F_{d, 3}$ & $0 \cdot 0020$ & - & $0 \cdot 0029$ & - & $0 \cdot 0030$ & - & $0 \cdot 0030$ & - & $0 \cdot 0013$ & - \\
\hline$F_{d}$ & $0 \cdot 0100$ & 1.0000 & $0 \cdot 0100$ & $1 \cdot 0000$ & $0 \cdot 0100$ & $1 \cdot 0000$ & $0 \cdot 0100$ & 1.0000 & $0 \cdot 0052$ & $1 \cdot 0000$ \\
\hline Overall & & 0.9669 & & 0.9682 & & 0.9682 & & 0.9682 & & 0.9502 \\
\hline Period & \multicolumn{2}{|c|}{$T_{1}=0.734 \mathrm{~s}$} & \multicolumn{2}{|c|}{$T_{1}=0.755 \mathrm{~s}$} & \multicolumn{2}{|c|}{$T_{1}=0.755 \mathrm{~s}$} & \multicolumn{2}{|c|}{$T_{1}=0.754 \mathrm{~s}$} & \multicolumn{2}{|c|}{$T_{1}=0.632 \mathrm{~s}$} \\
\hline
\end{tabular}


Table III. Optimal design for $v=0 \cdot 5,1,2$; Beams and columns have different sections

\begin{tabular}{|c|c|c|c|c|c|c|}
\hline \multirow[b]{2}{*}{ Criteria } & \multicolumn{2}{|c|}{$v=0.5$} & \multicolumn{2}{|c|}{$v=1$} & \multicolumn{2}{|c|}{$v=2$} \\
\hline & Value & $\mu$ & Value & $\mu$ & Value & $\mu$ \\
\hline \multicolumn{7}{|c|}{$5 \%$ risk with 1 -mode numerical integration } \\
\hline$B_{\text {beam }} / B_{\min }$ & 1.025 & $1 \cdot 0000$ & 1.025 & $1 \cdot 0000$ & $1 \cdot 025$ & $1 \cdot 0000$ \\
\hline$D_{\text {beam }} / D_{\min }$ & 1.830 & $1 \cdot 0000$ & $2 \cdot 200$ & $1 \cdot 0000$ & $2 \cdot 600$ & 1.0000 \\
\hline$B_{\text {col }} / B_{\min }$ & $1 \cdot 025$ & 1.0000 & 1.025 & 1.0000 & $1 \cdot 025$ & $1 \cdot 0000$ \\
\hline$D_{\mathrm{col}} / D_{\min }$ & $1 \cdot 350$ & $1 \cdot 0000$ & $1 \cdot 622$ & 1.0000 & 1.926 & $1 \cdot 0000$ \\
\hline$V / V_{\min }$ & $1 \cdot 252$ & 0.9357 & $1 \cdot 380$ & $0 \cdot 9030$ & $1 \cdot 521$ & $0 \cdot 8670$ \\
\hline$\sigma_{\max }^{b}$ & $0 \cdot 1947$ & 1.0000 & $0 \cdot 1521$ & $1 \cdot 0000$ & $0 \cdot 1423$ & 1.0000 \\
\hline$\sigma_{\max }^{c}$ & $0 \cdot 6312$ & $1 \cdot 0000$ & $0 \cdot 5467$ & 1.0000 & $0 \cdot 5057$ & $1 \cdot 0000$ \\
\hline$d_{\text {cade }}$ & $0 \cdot 0246$ & $1 \cdot 0000$ & $0 \cdot 0161$ & $1 \cdot 0000$ & $0 \cdot 0128$ & 1.0000 \\
\hline$F_{d, 1}$ & $0 \cdot 0263$ & - & $0 \cdot 0252$ & - & $0 \cdot 0238$ & - \\
\hline$F_{d, 2}$ & $0 \cdot 0500$ & - & $0 \cdot 0500$ & - & $0 \cdot 0500$ & - \\
\hline$F_{d, 2}$ & $0 \cdot 0140$ & - & $0 \cdot 0129$ & - & $0 \cdot 0119$ & - \\
\hline$F_{d}$ & $0 \cdot 0500$ & $1 \cdot 0000$ & $0 \cdot 0500$ & 1.0000 & $0 \cdot 0500$ & $1 \cdot 0000$ \\
\hline Overall & & 0.9926 & & $\mathbf{0 . 9 8 8 7}$ & & 0.9843 \\
\hline Period & \multicolumn{2}{|c|}{$T_{1}=1.396 \mathrm{~s}$} & \multicolumn{2}{|c|}{$T_{1}=1 \cdot 128 \mathrm{~s}$} & \multicolumn{2}{|c|}{$T_{1}=0.926 \mathrm{~s}$} \\
\hline \multicolumn{7}{|c|}{$1 \%$ risk with 1 -mode numerical integration } \\
\hline$B_{\text {beam }} / B_{\min }$ & $1 \cdot 025$ & $1 \cdot 0000$ & 1.025 & $1 \cdot 0000$ & $1 \cdot 025$ & $1 \cdot 0000$ \\
\hline$D_{\text {beam }} / D_{\text {min }}$ & $2 \cdot 751$ & $1 \cdot 0000$ & $3 \cdot 151$ & $1 \cdot 0000$ & $3 \cdot 515$ & $1 \cdot 0000$ \\
\hline$B_{\mathrm{col}} / B_{\min }$ & $1 \cdot 025$ & $1 \cdot 0000$ & 1.025 & $1 \cdot 0000$ & 1.025 & $1 \cdot 0000$ \\
\hline$D_{\mathrm{col}} / D_{\min }$ & $2 \cdot 031$ & $1 \cdot 0000$ & $2 \cdot 353$ & 1.0000 & $2 \cdot 679$ & $1 \cdot 0000$ \\
\hline$V / V_{\min }$ & $1 \cdot 572$ & $0 \cdot 8540$ & $1 \cdot 717$ & 0.8172 & $1 \cdot 855$ & $0 \cdot 7820$ \\
\hline$\sigma_{\max }^{b}$ & $0 \cdot 1405$ & $1 \cdot 0000$ & $0 \cdot 1364$ & $1 \cdot 0000$ & $0 \cdot 1333$ & $1 \cdot 0000$ \\
\hline$\sigma_{\max }^{c}$ & 0.4955 & $1 \cdot 0000$ & $0 \cdot 4660$ & $1 \cdot 0000$ & $0 \cdot 4400$ & $1 \cdot 0000$ \\
\hline$d_{\text {code }}$ & $0 \cdot 0120$ & $1 \cdot 0000$ & $0 \cdot 0101$ & 1.0000 & $0 \cdot 0088$ & 1.0000 \\
\hline$F_{d, 1}$ & $0 \cdot 0046$ & - & $0 \cdot 0042$ & - & $0 \cdot 0037$ & - \\
\hline$F_{d .2}$ & $0 \cdot 0100$ & - & $0 \cdot 0100$ & - & $0 \cdot 0100$ & - \\
\hline$F_{d, 3}$ & 0.0022 & - & $0 \cdot 0020$ & - & $0 \cdot 0017$ & - \\
\hline$F_{d}$ & $0 \cdot 0100$ & $1 \cdot 0000$ & $0 \cdot 0100$ & $1 \cdot 0000$ & $0 \cdot 0100$ & $1 \cdot 0000$ \\
\hline Overall & & 0.9826 & & 0.9778 & & 0.9730 \\
\hline Period & \multicolumn{2}{|c|}{$T_{1}=0.868 \mathrm{~s}$} & \multicolumn{2}{|c|}{$T_{1}=0.734 \mathrm{~s}$} & \multicolumn{2}{|c|}{$T_{1}=0.637 \mathrm{~s}$} \\
\hline
\end{tabular}

ratios for the beams and columns, $\sigma_{\max }^{b}$ and $\sigma_{\max }^{c}$, respectively, are less than 0.9 and the code interstorey-drift $d_{\text {code }}$ is lower than 2.7 per cent, so from the code point-of-view, they provide a fully satisfactory design (see Figures 2(e) and 2(f)). One can conclude from this fact that even for the lowest seismicity specified in Table III, the lifetime interstorey-drift reliability is less than 95 per cent for a purely code-based optimal design.

In Table IV, the effect on reliability-based optimal designs of increasing the importance weight, $w_{\mathrm{Vol}}$, for the building cost criterion is illustrated for the 5 and 1 per cent risk cases. At first, as $w_{\mathrm{Vol}}$ increases from 1 to 10 , the drift risk $F_{d}=5$ per cent (or $F_{d}=1$ per cent) continues to control the optimal design, which therefore does not change. When $w_{\mathrm{Vol}}=50$ (or 100), however, the cost criterion is influential in the trade-off and so a more 'aggressive' design with lower cost (or steel volume, $\left.V / V_{\min }\right)$ but higher risk, $F_{d}$, is produced. 
Table IV. Optimal design for $v=1$; Beams and columns have same sections

\begin{tabular}{|c|c|c|c|c|c|c|c|c|}
\hline \multirow[b]{2}{*}{ Criteria } & \multicolumn{2}{|c|}{$w_{\mathrm{Vol}}=1$} & \multicolumn{2}{|c|}{$w_{\mathrm{Vol}}=10$} & \multicolumn{2}{|c|}{$w_{\mathrm{Vol}}=50$} & \multicolumn{2}{|c|}{$w_{\mathrm{Vol}}=100$} \\
\hline & Value & $\mu$ & Value & $\mu$ & Value & $\mu$ & Value & $\mu$ \\
\hline \multicolumn{9}{|c|}{$5 \%$ risk with 1 -mode numerical integration } \\
\hline$B / B_{\min }$ & $1 \cdot 025$ & $1 \cdot 0000$ & $1 \cdot 025$ & $1 \cdot 0000$ & $1 \cdot 025$ & $1 \cdot 0000$ & $1 \cdot 025$ & $1 \cdot 0000$ \\
\hline$D / D_{\min }$ & 1.947 & $1 \cdot 0000$ & $1 \cdot 947$ & $1 \cdot 0000$ & $1 \cdot 758$ & $1 \cdot 0000$ & $1 \cdot 690$ & $1 \cdot 0000$ \\
\hline$V / V_{\min }$ & $1 \cdot 395$ & $0 \cdot 8992$ & $1 \cdot 395$ & 0.8992 & $1 \cdot 319$ & $0 \cdot 9186$ & $1 \cdot 292$ & $0 \cdot 9255$ \\
\hline$F_{d, 1}$ & $0 \cdot 0163$ & - & $0 \cdot 0163$ & - & $0 \cdot 0251$ & - & $0 \cdot 0294$ & - \\
\hline$F_{d, 2}$ & $0 \cdot 0500$ & - & $0 \cdot 0500$ & - & $0 \cdot 0730$ & - & $0 \cdot 0840$ & - \\
\hline$F_{d, 3}$ & $0 \cdot 0179$ & - & $0 \cdot 0179$ & - & 0.0273 & - & $0 \cdot 0319$ & - \\
\hline$F_{d}$ & $0 \cdot 0500$ & $1 \cdot 0000$ & $0 \cdot 0500$ & $1 \cdot 0000$ & 0.0730 & 0.5394 & $0 \cdot 0840$ & $0 \cdot 3195$ \\
\hline Overall & & 0.9738 & & 0.9216 & & 0.9123 & & 0.9174 \\
\hline Period & \multicolumn{2}{|c|}{$T_{1}=1 \cdot 106 \mathrm{~s}$} & \multicolumn{2}{|c|}{$T_{1}=1 \cdot 106 \mathrm{~s}$} & \multicolumn{2}{|c|}{$T_{1}=1.246 \mathrm{~s}$} & \multicolumn{2}{|c|}{$T_{1}=1.304 \mathrm{~s}$} \\
\hline \multicolumn{9}{|c|}{$1 \%$ risk with 1 -mode numerical integration } \\
\hline$B / B_{\min }$ & $1 \cdot 025$ & $1 \cdot 0000$ & $1 \cdot 025$ & $1 \cdot 0000$ & 1.025 & $1 \cdot 0000$ & 1.025 & 1.0000 \\
\hline$D / D_{\min }$ & 2.797 & $1 \cdot 0000$ & 2.797 & $1 \cdot 0000$ & 2.574 & $1 \cdot 0000$ & $2 \cdot 508$ & $1 \cdot 0000$ \\
\hline$V / V_{\min }$ & 1.735 & $0 \cdot 8125$ & 1.735 & $0 \cdot 8125$ & $1 \cdot 646$ & $0 \cdot 8353$ & $1 \cdot 619$ & $0 \cdot 8421$ \\
\hline$F_{d, 1}$ & 0.0025 & - & 0.0025 & - & $0 \cdot 0042$ & - & $0 \cdot 0048$ & - \\
\hline$F_{d, 2}$ & $0 \cdot 0100$ & - & $0 \cdot 0100$ & - & $0 \cdot 0153$ & - & $0 \cdot 0173$ & - \\
\hline$F_{d, 3}$ & 0.0029 & - & 0.0029 & - & 0.0047 & - & 0.0055 & - \\
\hline$F_{d}$ & $0 \cdot 0100$ & $1 \cdot 0000$ & $0 \cdot 0100$ & 1.0000 & 0.0153 & $0 \cdot 4710$ & $0 \cdot 0173$ & 0.2679 \\
\hline Overall & & 0.9494 & & 0.8524 & & 0.8319 & & 0.8355 \\
\hline Period & \multicolumn{2}{|c|}{$T_{1}=0.722 \mathrm{~s}$} & \multicolumn{2}{|c|}{$T_{1}=0.722 \mathrm{~s}$} & \multicolumn{2}{|c|}{$T_{1}=0.797 \mathrm{~s}$} & \multicolumn{2}{|c|}{$T_{1}=0.822 \mathrm{~s}$} \\
\hline
\end{tabular}

\section{CONCLUSIONS}

The proposed optimal design methodology provides a rational basis for incorporating seismic load uncertainties in the design process and to make reliability-based optimal design decisions that meet specified multiple criteria, including performance-based structural criteria. Code-based requirements are also easily incorporated into the process. This new framework is well suited for performance-based design of structures under uncertainty. Although the optimal design framework has been demonstrated for a special class of ground motion and structural models, it is very flexible and more sophisticated models can easily be treated. For example, advances in ground motion attenuation formulas and seismic hazard models can easily be incorporated into the framework; inelastic finite-element analysis tools can be included along with reliability approximations for non-linear systems to more realistically treat large deformations; and the methodology can be extended to include loading uncertainties due to wind, as well as structural modelling uncertainties.

It should be noted that for a relatively large number of design parameters, the search for an optimal design may involve a large amount of computational effort. This effort also depends on the sophistication of the ground motion model, structural model (linear or non-linear hysteretic), the type of the reliability analysis performed (component or system reliability), and the optimization algorithm used. In addition, optimization methodologies do not guarantee that a global 
optimum will be obtained. However, the optimization algorithms proposed are well suited for at least finding better designs within an extensive design parameter space compared with a preliminary design based on engineering judgement. In practice, the capability of finding a more preferred design than an initial one may be sufficient, rather than expending a great deal of computational effort to find a globally optimal one, particularly since there are usually diminishing returns as the design iterations proceed.

The general framework presented here for multi-criteria optimal design under risk is potentially applicable to a wide range of engineering systems, including buildings, bridges, offshore structures, equipment and piping systems. In fact, the basic methodology has wider applicability for multi-criteria decision making under risk.

\section{ACKNOWLEDGEMENTS}

This paper is based upon work supported by the California Universities for Research in Earthquake Engineering under the CUREe-Kajima Research Program and by the National Science Foundation under grant CMS-9796135. The CODA software package was developed as a team effort by the authors with H. A. Smith, V. Vance and L. Barroso of Stanford University and S. F. Masri and W. M. Xu of University of Southern California.

\section{REFERENCES}

1. J. L. Beck, E. Chan, A. Irfanoglu, S. Masri, W. M. Xu, H. A. Smith, V. Vance and L. Barroso, 'New computer tools for optimal design decisions in the presence of risk', Final Report on CUREe-Kajima Project, Caltech-USC-Stanford, CA, 1996.

2. J. L. Beck, C. Papadimitriou, E. Chan and A. Irfanoglu, 'Reliability-based optimal design decisions in the presence of seismic risk', Proc. 11th World Conf. on Earthquake Engr., Paper No. 1058, Elsevier Science Ltd., Amsterdam, 1996.

3. A. H.-S. Ang, A. Der Kiureghian, F. Filippou, J. Pires and E. Polak, 'Reliability based optimal aseismic design of reinforced concrete buildings', Final Report on CUREe-Kajima Project, UC Berkeley-UC Irvine, CA, 1996.

4. Y. K. Wen, 'Building reliability and code reliability', Earthquake Spectra 11(2), 269-296 (1995).

5. A. H.-S. Ang and C. A. Cornell, 'Reliability bases of structural safety and design', J. Struct. Engng., ASCE 100(ST9), 1755-1769 (1974).

6. F. Moses and D. E. Kisner, 'Optimal structural design with failure probability constraints', AIAA J. 5(6), 1152-1158 (1967).

7. D. M. Frangopol, 'Multicriteria reliability-based optimum design', Struct. Safety 3(1), 23-28 (1985).

8. F. Casciati and L. Faravelli, 'Structural reliability and structural design optimization', in I. Konishi et al. (eds), 4th Int. Conf. on Structural Safety and Reliability, Vol. III, 1985, pp. 61-70.

9. P. Thoft-Christensen and Y. Murotsu, Application of Structural Systems Reliability Theory, Springer, New York, 1986.

10. G. Fu and D. M. Frangopol, 'Balancing weight, system reliability and redundancy in a multiobjective optimization framework', Struct. Safety 7, 165-175 (1990).

11. G. Fu and D. M. Frangopol, 'Reliability-based vector optimization of structural systems', J. Struct. Engng., ASCE 116(8), 2141-2161 (1990).

12. H. Adeli (ed), Advances in Design Optimization, Chapman \& Hall, New York, 1994.

13. J. L. Cohon, Multiobjective Programming and Planning, Academic Press, New York, 1978.

14. AISC, Manual of steel construction-ASD, American Institute of Steel Construction, Chicago, 1989.

15. R. L. Keeney and H. Raiffa, Decisions with Multiple Objectives: Preferences and Value Trade-offs, Wiley, New York, 1976.

16. K. Otto, 'A formal representation theory for engineering design', Ph.D. Thesis in Mechanical Engineering, California Institute of Technology, Pasadena, CA, 1992.

17. E. Chan, 'Optimal design of building structures using genetic algorithms', Ph.D. Thesis in Civil Engineering, EERL Report No. 97-06, California Institute of Technology, Pasadena, CA, 1997.

18. S. F. Masri, G. A. Bekey and F. B. Safford, 'An adaptive random search method for identification of large scale nonlinear systems, presented at the 4th IFAC Symp. on Identification and System Parameter Estimation, Tbilisi, USSR, 1976.

19. W. H. Press, B. P. Flannery, S. A. Teukolsky and W. T. Vetterling, Numerical Recipes, Cambridge University Press, New York, 1986. 
20. A. Der Kiureghian and J. B. Ken, 'The stochastic finite element method in structural reliability', Probabilistic Engng. Mech. 3(2), 93-91 (1988).

21. C. Papadimitriou, L. S. Katafygiotis and J. L. Beck, 'Approximate analysis of response variability of uncertain linear systems', Probabilistic Engng. Mech. 10, 251-264 (1995).

22. G. I. Schuëller and R. Stix, 'A critical appraisal of methods to determine failure probabilities', Struct. Safety 4, 293-309 (1987).

23. C. G. Bucher, 'Adaptive sampling - an iterative fast Monte Carlo procedure', Struct. Safety 5, 119-126 (1988).

24. C. Papadimitriou, J. L. Beck and L. S. Katafygiotis, 'Asymptotic expansions for reliability and moments of uncertain dynamic systems', EERL Report No. 95-05, California Institute of Technology, Pasadena, CA, 1995.

25. C. Papadimitriou, J. L. Beck and L. S. Katafygiotis, 'Asymptotic expansions for reliability and moments of uncertain systems', J. Engng. Mech. ASCE 123(12) (1997).

26. H. O. Madsen, S. Krenk and N. C. Lind, Methods of Structural Safety, Prentice-Hall, New Jersey, 1986.

27. A. Der Kiureghian, H.-Z. Lin and S.-J. Hwang, 'Second-order reliability approximations', J. Engng. Mech. ASCE 113(8), 1208-1225 (1987).

28. K. Breitung, 'Asymptotic approximations for probability integrals', Probabilistic Engng. Mech. 4(4), 187-190 (1989).

29. L. Faravelli, 'A response surface approach for reliability analysis', J. Engng. Mech. ASCE 115(12), 2763-2781 (1989).

30. ICBO, Uniform Building Code, International Conference of Building Officials, Whittier, CA, 1994.

31. D. M. Boore, W. B. Joyner and T. E. Fumal, 'Estimation of response spectra and peak accelerations from western North American earthquakes: an interim report', USGS Open-File Report 93-509, U.S. Geological Survey, Menlo Park, CA, 1993.

32. D. M. Boore, W. B. Joyner and T. E. Fumal, 'Estimation of response spectra and peak accelerations from western North American earthquakes: an interim report part 2', USGS Open-File Report 94-127, U.S. Geological Survey, Menlo Park, CA, 1994.

33. B. Gutenberg and C. Richter, 'Earthquake magnitude, intensity and acceleration', Bull. Seism. Soc. Am. 46(2), 105-145 (1958).

34. A. Der Kiureghian, 'Seismic risk analysis of structural systems', J. Engng. Mech. ASCE, 107, 1133-1153 (1981).

35. J. L. Beck, C. Papadimitriou, E. Chan and A. Irfanoglu, 'A performance-based optimal structural design methodology', EERL Report No. 97-03, California Institute of Technology, Pasadena, CA, 1997. 